\title{
TiO2 Nanofibers Decorated with Monodispersed W03 Heterostruture Sensors for High Gas Sensing Performance Towards H2 Gas
}

M Kumaresan ( $\square$ kumaresan084@gmail.com )

Hindusthan College of Arts and Science https://orcid.org/0000-0001-6456-9181

\section{Venkatachalam}

Erode Arts and Science College

\section{Saroja}

Erode Arts and Science College

P. Gowthaman

Erode Arts and Science College

\section{Research Article}

Keywords: WO3, TiO2 nanofibers, Heterojunction, Chemical sensor, Hydrogen gas, High sensitivity

Posted Date: March 13th, 2021

DOl: https://doi.org/10.21203/rs.3.rs-285097/v1

License: (c) (i) This work is licensed under a Creative Commons Attribution 4.0 International License. Read Full License 


\section{Abstract}

A simple spin coating method was used to prepare the $\mathrm{WO}_{3}-\mathrm{TiO}_{2}$ heterostructural nanofibers (HNFs). Various kinds of techniques, including XRD, SEM, TEM, EDS and XPS, have described the structures, chemical constitutions and morphologies of the samples. Following the decoration of the $\mathrm{WO}_{3}$ nanocubes on the surface of $\mathrm{TiO}_{2}$ nanofibers, XPS findings confirmed the presence of $\mathrm{W}^{5+}$ and the excess proportion of both chemisorbed reactive oxygen and oxygen vacancies. $\mathrm{WO}_{3}$ incorporated $\mathrm{TiO}_{2}$ thin film sensor showed high sensing response (78\%), rapid response (20 s) and recovery time (23 s) with respect to other gas molecules $\left(\mathrm{NH}_{3}, \mathrm{NO}_{2}, \mathrm{LPG}\right.$ and $\left.\mathrm{SO}_{2}\right)$. The finding demonstrates that the $\mathrm{WO}_{3}-\mathrm{TiO}_{2}$ sensor showed good selective response towards $\mathrm{H}_{2}$ gas. A unique path was created by this work to build hetero-highly ordered mesoporous metal oxides junctions for applications in $\mathrm{H}_{2}$ gas sensor based devices.

\section{Introduction}

With the need to identify the amount of toxic gases $\left(\mathrm{NO}, \mathrm{NO}_{2}, \mathrm{CO}, \mathrm{SO}_{2}, \mathrm{H}_{2} \mathrm{~S}\right.$, etc.) in the air in real time, the development of high-performance gas sensors in the manufacturing, ecological and health sectors is essential. Due to its benefits such as simple design, long lifetime, compact size and $\mathrm{n}$, the semiconductor gas sensor is one of the most popular consistently applied sensors [1,2]. The core part of the semiconductor gas sensor as a sensitive coating. A multitude of compounds, such as $\mathrm{ZnO}[3,4], \mathrm{SnO}_{2}[5$, $6]$ and $\mathrm{Fe}_{2} \mathrm{O}_{3}[7,8]$, were used to manufacture gas-sensitive coatings. However these frameworks have some drawbacks, such as low response, high energy consumption, and some humidity and temperature volatility. $\mathrm{WO}_{3}$ has exceptionally high sensitivity for $\mathrm{NO}_{2}$ detection compared to the conventional materials above $[9,10]$, and is a suitable candidate for gas sensor coating materials. And it is also stated that the doping into $\mathrm{WO}_{3}$ of another kind of oxides leads to the formation of semiconductor heterojunction, thereby increasing overall the coatings' gas sensitivity.

$\mathrm{TiO}_{2}$ is well established to be a kind of semiconductor material with excellent electrical properties. Improvements have been documented in the gas sensitivity of semiconductor $\mathrm{WO}_{3}$ induced by $\mathrm{TiO}_{2}$ doping. However, the latest $\mathrm{TiO}_{2}$ doping methods, which are not suitable for commercial development, are highly complex. In fact, the gas control problem of the $\mathrm{TiO}_{2}$-doped coatings has still not been clearly established. The $\mathrm{WO}_{3}$-based composite coatings doped with $\mathrm{TiO}_{2}$ were prepared by liquid-phase plasma spraying in this paper as per that concern, and the gas-sensing process of $\mathrm{TiO}_{2}-\mathrm{WO}_{3}$ composite coatings was extensively investigated. As already mentioned, it is also proved to be a potential method is tested loaded on a support material due to its delicate conductivity, strong catalytic properties, and remarkable chemical inertness. Nanofiber $\mathrm{WO}_{3}-\mathrm{TiO}_{2}$ may form n-n heterojunction, which can potentially present highly explosive localized areas and thus obtain unpredictable features for specific applications. In this analysis, we describe a simple and successful spin coating technique has been used to fabricated the quasi-1D $\mathrm{WO}_{3}$ nanoparticles-decorated $\mathrm{TiO}_{2}$ heterostructural nanofibers. High response, discern 
specificity, quick response time and recovery time for $\mathrm{H}_{2}$ gas were demonstrated by the as-prepared $\mathrm{WO}_{3}-$ $\mathrm{TiO}_{2}$ material, making it a successful candidate for application in $\mathrm{H}_{2}$ sensors. A sensor adsorption and reaction model has also been suggested. The increase in the efficiency of gas sensing can be due to the creation of heterojunctions seen between two material types.

\section{Experimental Process}

\subsection{Chemicals and Reagents}

Tungsten chloride $\left(\mathrm{WCl}_{6}\right)$, Titanium tetra-isopropoxide (TTIP) with a normal purity of $97 \%$ (Aldrich, UK), Ammonia solution $\left(\mathrm{NH}_{4} \mathrm{OH}\right)$, Hydrochloric acid $(\mathrm{HCl})$ was purchased and used as without extra purification.

\subsection{Preparation of $\mathrm{WO}_{3} / \mathrm{TiO}_{2}$ thin films}

The process of making $\mathrm{WO}_{3} / \mathrm{TiO}_{2}$ films involves two step synthesis processes. Hydrothermal and spin coating technique has been used to fabricate the bare $\mathrm{WO}_{3}$ and $\mathrm{TiO}_{2}$ thin films, respectively. Firstly, $\mathrm{WCl}_{6}$ was distributed in $30 \mathrm{~mL}$ deionized water through magnetic stirring for $20 \mathrm{~min}$. Later, $5 \mathrm{~mL}$ of $\mathrm{HCl}$ aqueous solution was added and the reaction mixture was fully dissolved by thoroughly mixing for another $10 \mathrm{~min}$. the reaction mixture was adapted to hydrothermal reaction $\left(180^{\circ} \mathrm{C} / 12 \mathrm{~h}\right)$ and finally dried $\left(80^{\circ} \mathrm{C} / 12 \mathrm{~h}\right)$ for further use. Spin coating method was used to fabricate the $\mathrm{TiO}_{2}$ nanotubes. $\mathrm{FTO}$ substrate was used to deposit the thin films. The raw materials of $\mathrm{TiO}_{2}$ precursors ( $5 \mathrm{~mL}$ TTIP with 1:1 ratio of ethanol and DI water) was deposited on FTO glass substrate at speed of $2000 \mathrm{rpm}$ for $1 \mathrm{~min}$. The films after drying at $120^{\circ} \mathrm{C}$ for 5 min are subsequently heat-treated at $450^{\circ} \mathrm{C}$ for 30 min in nitrogen flow. In the process of $\mathrm{WO}_{3} / \mathrm{TiO}_{2}$ composite. The prepared $\mathrm{WO}_{3}$ nanopowder $(0.5 \mathrm{~g})$ was dispersed in the $0.5 \mathrm{~g}$ of $\mathrm{TiO}_{2}$ nanofibers and same experimental process of spin coating method has been repeated for each concentrations. The films with $\mathrm{WO}_{3}$ nanoparticles, $\mathrm{TiO}_{2}$ nanofibers and $\mathrm{WO}_{3} / \mathrm{TiO}_{2}$ heterostrutures were labeled as $\mathrm{WO}_{3} \mathrm{NPs}, \mathrm{TiO}_{2} \mathrm{NFs}$ and $\mathrm{WO}_{3} / \mathrm{TiO}_{2} \mathrm{Hs}$, respectively.

\subsection{Gas sensor set up with sensor region}

The gas sensor of the resistive form was constructed and the schematic view is being shown in Fig. 1 . The detailed description of the sensor was mentioned already our previous reported work [11]. The mass flow controller (MFC) was used to modify gas concentrations at various ppm levels (0-1000 ppm). The gases were connected to the mass flow controller with a mixer from different cyclinder. The diluted gases were then evenly located in the testing reactor. The gas sensing response $(S)$ was stated as $\left(R_{G}-R_{A}\right) / R_{A} x$ $100 \%$ [12], where the air resistance value and the corresponding gas were $R_{G}$ and $R_{A}$, respectively.

\section{Results And Discussion}

\subsection{X-ray diffraction (XRD) analysis}


Figure 2 shows the XRD pattern of $\mathrm{WO}_{3} \mathrm{NPs}, \mathrm{TiO}_{2} \mathrm{NFs}$ and $\mathrm{WO}_{3} / \mathrm{TiO}_{2} \mathrm{Hs}$ films respectively. The pattern clearly expose the bare $\mathrm{WO}_{3}$ and $\mathrm{TiO}_{2}$ are monoclinic (JCPDS card No. 43-1035) and anatase phase tetragonal rutile type structure (JCPDS card No. 21-1272). Sharp intense peaks without any contaminant suggest that fabricated films are high order crystalline nature. The diffraction peaks of the $\mathrm{WO}_{3}-\mathrm{TiO}_{2}$ can be indexed to the mixed $\mathrm{WO}_{3}$ and $\mathrm{TiO}_{2}$ with different phases and no apparent peak change relative to the pure materials, which shows that the end product contains of it rather than alloy $\mathrm{WO}_{3}$ and $\mathrm{TiO}_{2}$ nanocomposites.

\subsection{Morphological studies}

The morphological detection of the sensors was examined by SEM and TEM. Figure 2 (a-c) shows the SEM images of $\mathrm{WO}_{3} \mathrm{NPs}, \mathrm{TiO}_{2} \mathrm{NFs}$ and $\mathrm{WO}_{3} / \mathrm{TiO}_{2} \mathrm{Hs}$ films respectively. Monodispered spherical of $\mathrm{WO}_{3}$ and tubes like $\mathrm{TiO}_{2}$ morphologies are recognized by the SEM images. Further the clear morphological view was identified their corresponding TEM images. The TEM image of $\mathrm{WO}_{3}$ and $\mathrm{TiO}_{2}$ clearly demonstrate that less aggregated nanoparticles with uniform tube like morphologies were found. In the $\mathrm{WO}_{3} / \mathrm{TiO}_{2}$ heterostruture composite, the nanoparticles are uniformly grown on the surface of the $\mathrm{TiO}_{2}$ nanotubes. Without obvious aggregation and combining, the framework of $\mathrm{TiO}_{2}$ nanofibers is advantageous for getting high surface area and improving the catalytic process of gas sensing. The elemental mapping of $\mathrm{WO}_{3} / \mathrm{TiO}_{2} \mathrm{Hs}$ films shows $\mathrm{W}$, Ti and $\mathrm{O}$ elements on the surface of the images (Fig. 3g-i).

\subsection{Surface and elemental composition studies}

Brunauer-Emmett-Teller (BET) method was used to describe the porous structure and clear surface areas of sensors through their $\mathrm{N}_{2}$ adsorption-desorption analysis as well as pore size distribution curve (Fig. $4 a \&$ b). All the samples display category IV nitrogen isotherm with a hysteresis loop, suggesting the features of mesopores [13-17]. Due to the heterostruture combination of $\mathrm{WO}_{3}$ nanoparticles and $\mathrm{TiO}_{2}$ nanofibers can deliver the high surface area $\left(104.7 \mathrm{~m}^{2} / \mathrm{g}\right)$ and pore size $(17.4 \mathrm{~nm})$ ) than that of bare $\mathrm{WO}_{3}$ $\left(54.3 \mathrm{~m}^{2} / \mathrm{g}\right.$ and $\left.37.4 \mathrm{~nm}\right)$ and $\mathrm{TiO}_{2}\left(77 \mathrm{~m}^{2} / \mathrm{g}\right.$ and $\left.30.2 \mathrm{~nm}\right)$. The chemical state and composition of elemental configuration was analyzed by XPS. The survey XPS of $\mathrm{WO}_{3} / \mathrm{TiO}_{2} \mathrm{Hs}$ shows the chief elements of $\mathrm{W}, \mathrm{Ti}$ and $\mathrm{O}$ (Fig. 5a). Figure 5 (b-d) displays the high resolution spectrum of the $\mathrm{W} 4 \mathrm{f}, \mathrm{Ti} 2 \mathrm{p}$ and $\mathrm{O}$ 1s spectra. The divided peaks based at the binding energies of 34.9 and $36.8 \mathrm{eV}$ correspond to the standard binding energies of $W^{5+}[18,19]$ in the $W 4 f$ XPS spectrum. With binding energies at $465.2 \mathrm{eV}$ and 459.6 eV, the Ti $2 p$ XPS spectrum can be deconvoluted into two major peaks, corresponding to Ti $2 \mathrm{p}_{1 / 2}$ and Ti $2 \mathrm{p}_{3 / 2}$. The distinctiveness peaks of $\mathrm{O}_{2}{ }^{-}$and $\mathrm{O}^{-}$are located with equivalent binding energies of $530.4 \mathrm{eV}$ and $531.5 \mathrm{eV}$, respectively $[20,21]$.

\subsection{Gas sensing test}

The efficiency of the gas sensing performance of the $\mathrm{H}_{2}$ gas was tested by using the $\mathrm{WO}_{3}, \mathrm{TiO}_{2}$ and $\mathrm{WO}_{3} / \mathrm{TiO}_{2}$ sensor materials. Before gas sensing test the sensor samples were exposed to air atmosphere 
to identify the resistivity performance of the samples and the relevent graph illustrate that good rsisitive nature for all the sensor samples (Fig. 6a). The sensing response is shown in Fig. 6 (b). The dynamic response is drqastically enhanced with the increase of $\mathrm{H}_{2}$ gas concentration from 0 to $1000 \mathrm{ppm}$ (Fig. 6c). The maximum sensitiviy is achived by $\mathrm{WO}_{3} / \mathrm{TiO}_{2} \mathrm{Hs}(78 \%)$ than compared with bare $\mathrm{WO}_{3}(27 \%)$ and $\mathrm{TiO}_{2}(52 \%)$ sensor films. In addition, the impact of the degree of doping on the ordered quality of the porous channel and relative humidity $(\mathrm{RH})$ on sensing characteristics was also investigated and the relevent plot is shown in Fig. 7 (a). The analysis indicate that the sensor based on $\mathrm{WO}_{3} / \mathrm{TiO}_{2} \mathrm{Hs}$ offered the highest response, regardless of the test conditions. The high performance of the $\mathrm{WO}_{3} / \mathrm{TiO}_{2} \mathrm{Hs}$ based sensor ought to be beneficial for the unique and powerful structure effect and doping effect because the mesoporous structure could provide both high surface area and prosperous for hydrogen gas adsorption and diffusion (structure effect) while doping means improving defects and active site. For industrial cases, the reaction and recovery time of gas sensors is quite important. $\mathrm{The}_{2}$ gas concnetrtion I exposed to $1000 \mathrm{ppm}$ at RT towards the all the sensor films and the finding reveals that $\mathrm{WO}_{3} / \mathrm{TiO}_{2} \mathrm{Hs}$ sensors gained rapid response (20s) and recovery time (23 s) than other sensors (Fig. 7b-d). The $\mathrm{H}_{2}$ gas parameters of all the sensors are estimated and the values are displayed in Table 1. Finally, we carried out a response comparison of the sensors $1000 \mathrm{ppm}$ of different target gases to affirm the progress in selectivity. Figure $8(\mathrm{a}-\mathrm{c})$ selectivity charecteristics graph of all the sensors, which is exposed to various target gases like, $\mathrm{NH}_{3}, \mathrm{NO}_{2}, \mathrm{LPG}$ and $\mathrm{SO}_{2}$. The sensor stability is often continually monitored. As shown in Fig. 8d, the curve showed a remarkably stable tendency toward $1000 \mathrm{ppm} \mathrm{H}_{2}$ gas throughout a 60-day long-term stability calculation. In addition, no noticeable decline in response pattern is found for detecting $1000 \mathrm{ppm} \mathrm{H} \mathrm{H}_{2}$ gas after 50 successive tests (Fig. 8d). These findings show that the HNFs-based $\mathrm{WO}_{3} / \mathrm{TiO}_{2}$ sensor has strong reproducibility and long-term reliability. The sensing mechanism with graphical sketch of the proposed sensor is shown in Fig. 9. The improved sensing performance of the HNFs-based $\mathrm{WO}_{3} / \mathrm{TiO}_{2}$ sensor is due to the following reasons: On the one side, the Fermi level of $\mathrm{WO}_{3}$ is lower for $\mathrm{WO}_{3} / \mathrm{TiO}_{2} \mathrm{HNFs}$ than for $\mathrm{TiO}_{2}$, which contributes to the transport of energy from $\mathrm{TiO}_{2}$ to $\mathrm{WO}_{3}$ till the level of Fermi energy is equivalent. As a consequence, on the side of $\mathrm{WO}_{3}$, the electron diffusion surface will develop, that will make it much easier to accumulate oxygen or target gasses on the $\mathrm{WO}_{3}$. Consequently, $\mathrm{WO}_{3}$ nanospherical serve as a responsive active site on the surface of $\mathrm{TiO}_{2}$ nanotubes and have a beneficial effect on $\mathrm{H}_{2}$ sensor output. It is clearly suggest that the gas sensing efficiency of this sensor is obviously advantageous over that of other sensors.

\section{Conclusions}

In this report, the $\mathrm{WO}_{3}$ nanoparticles incorporated $\mathrm{TiO}_{2}$ heterostruuctures with mesoporous nature films sensors were fabricated and tested the gas sensing response towards €h2 gas with at RT. The heterostruture which facilitated the fabrication of a sensitive and porous shaped sensing film. $\mathrm{WO}_{3} / \mathrm{TiO}_{2}$ heterostructure thin film sensor showed high sensing response (78\%), rapid response (20 s) and recovery time (23 s) with respect to other gas molecules $\left(\mathrm{NH}_{3}, \mathrm{NO}_{2}, \mathrm{LPG}\right.$ and $\left.\mathrm{SO}_{2}\right)$. In addition that the fabricated sensors also exhibits long term stability due no apparent loss in sensitivity after multiple cycle 
experiments. The finding demonstrates that the $\mathrm{WO}_{3}-\mathrm{TiO}_{2}$ sensor showed good selective response towards $\mathrm{H}_{2}$ gas. The $\mathrm{WO}_{3}-\mathrm{TiO}_{2} \mathrm{HNFs}$ sensor's excellent performance could be related to the existence of $n-n$ junctions as well as the redox of $\mathrm{W}^{6+}$ and $\mathrm{W}^{5+}$ states. The results confirmed that the significant insight $\mathrm{WO}_{3}-\mathrm{TiO}_{2} \mathrm{HNFs}$ was a good approach for a high-performance $\mathrm{H}_{2}$ sensor.

\section{References}

1. Franke ME, Koplin TJ, Simon U. Metal and metal oxiden anoparticles in chemiresistors: does the nanoscale matter? Small. 2 (2006) 36-50.

2. Tricoli A, Righettoni M, Teleki A. Semiconductor gas sensors:dry synthesis and application. Angew Chem Int Ed. 49 (2010) 7632-7659.

3. Wan Q, Li QH, Chen YJ, Wang TH, He XL, Li JP, et al.Fabrication and ethanol sensing characteristics of ZnOnanowire gas sensors. Appl. Phys. Lett. 84 (2004) 3654-3656.

4. Zhang J, Wang S, Wang Y, Xu M, Xia H, Zhang S, et al. ZnOhollow spheres: preparation characterization, and gassensing properties. Sens Actuators B: Chem. 139 (2009) 411-417.

5. Wei F, Zhang H, Nguyen M, Ying M, Gao R, Jiao Z.Template-free synthesis of flower like $\mathrm{SnO}_{2}$ hierarchical nanostructures with improved gas sensing performance. Sens Actuators B: Chem. 215 (2015) 15-23.

6. Sun P, Cao Y, Liu J, Sun Y, Ma J, Lu G. Dispersive $\mathrm{SnO}_{2}$ nanosheets: hydrothermal synthesis and gassensingproperties. Sens. Actuators B: Chem. 156 (2011) 779-783.

7. Chen J, Xu LN, Li WY, Gou XG. a-Fe $\mathrm{O}_{2} \mathrm{O}_{3}$ nanotubes in gas sensor and lithium-ion baterry applications. Adv. Mater. 17 (2005) 582-586.

8. Ouyang J, Pei J, Kuang Q, Xie Z, Zheng L. Supersaturation-controlled shape evolution of alpha- $\mathrm{Fe}_{2} \mathrm{O}_{3}$ nanocrystals and their facet-dependent catalytic and sensing properties. ACS Appl. Mater. Interfaces. 6 (2014) 12505-12514.

9. Espid E, Taghipour F. Development of highly sensitive $\mathrm{ZnO} / \mathrm{In}_{2} \mathrm{O}_{3}$ composite gas sensor activated by UV-LED. Sens Actuators B. 241 (2016) 828-839.

10. Baranov A, Spirjakin D, Akbari S, Somov A. Optimization of power consumption for gas sensor nodes: a survey. Sens. Actuators A. 233 (2015) 279-289.

11. K.H. Kim, M. Yang, K.M. Cho, Y.S. Jun, S.B. Lee, H.T. Jung, High quality reduced graphene oxide through repairing withmulti-layered graphene ball nanostructures,Nat. Sci. Rep. 3 (2013) 3251-3258.

12. S. Ryabtsev, A. Shaposhnick, A. Lukin, E. Domashevskaya, Sensors and Actuators B: Chemical. 59 (1999) 26.

13. M. Sumathi, A. Prakasam, P.M. Anbarasan, High capable visible light driven photocatalytic activity of $\mathrm{WO}_{3} / \mathrm{g}-\mathrm{C}_{3} \mathrm{~N}_{4}$ hetrostructure catalysts synthesized by a novel one step microwave irradiation route, $\mathrm{J}$. Mater. Sci. Mater. Electron. 30 (2019) 3294-3304. 
14. M. Sumathi, A. Prakasam, P.M. Anbarasan, Fabrication of hexagonal disc shaped nanoparticles g$\mathrm{C}_{3} \mathrm{~N}_{4} / \mathrm{NiO}$ heterostructured nanocomposites for efficient visible light photocatalytic performance, Journal of Cluster Science 30 (2019) 757-766.

15. M. Parthibavarman, S. Sathishkumar, M. Jayashree, R. BoopathiRaja, Microwave Assisted Synthesis of Pure and Ag Doped $\mathrm{SnO}_{2}$ Quantum Dots as Novel Platform for High Photocatalytic Activity Performance, Journal of Cluster Science 30 (2019) 351-363

16. M. Parthibavarman, S. Sathishkumar, S. Prabhakaran, M. Jayashree, R. BoopathiRaja, High visible light-driven photocatalytic activity of large surface area $\mathrm{Cu}$ doped $\mathrm{SnO}_{2}$ nanorods synthesized by novel one-step microwave irradiation method, Journal of the Iranian Chemical Society 15 (2018) 2789-2801

17. R. BoopathiRaja, M. Parthibavarman, Hetero-structure arrays of $\mathrm{MnCo}_{2} \mathrm{O}_{4}$ nanoflakes@ nanowires grown on Ni foam: Design, fabrication and applications in electrochemical energy storage, J. Alloy. Compd. 811 (2019) 152084

18. N. Feng, Q. Wang, A. Zheng, Z. Zhang, J. Fan, S.B. Liu, et al., Understanding the high photocatalytic activity of $(\mathrm{B}, \mathrm{Ag})$-codoped $\mathrm{TiO}_{2}$ under solar-light irradiation with XPS, solid-state NMR, and DFT calculations, J. Am. Chem. Soc. 135 (4) (2013) 1607-1616,

19. Y. Zhang, J. Chen, L. Hua, S. Li, X. Zhang, W. Sheng, et al., High photocatalytic activity of hierarchical $\mathrm{SiO}_{2} @ \mathrm{C}$-doped $\mathrm{TiO}_{2}$ hollow spheres in UV and visible light towards degradation of of rhodamine $\mathrm{B}, \mathrm{J}$. Hazard. Mater. 15 (20170 309-318

20. J.-C. Dupin, D. Gonbeau, P. Vinatier, A. Levasseur, Systematic XPS studies of metal oxides, hydroxides and peroxides, Phys. Chem. Chem. Phys. 2 (2000) 1319-1324.

21. R. Sivakumar, R. Gopalakrishnan, M. Jayachandran, C. Sanjeeviraja, Investigation of X-ray photoelectron spectroscopic (XPS), cyclic voltammetric analyses of WO3 films and their electrochromic response in FTO/WO3/electrolyte/FTO cells, Smart Mater. Struct. 15 (2006) 877-888

\section{Table}

Due to technical limitations, table 1 is only available as a download in the Supplemental Files section.

\section{Figures}




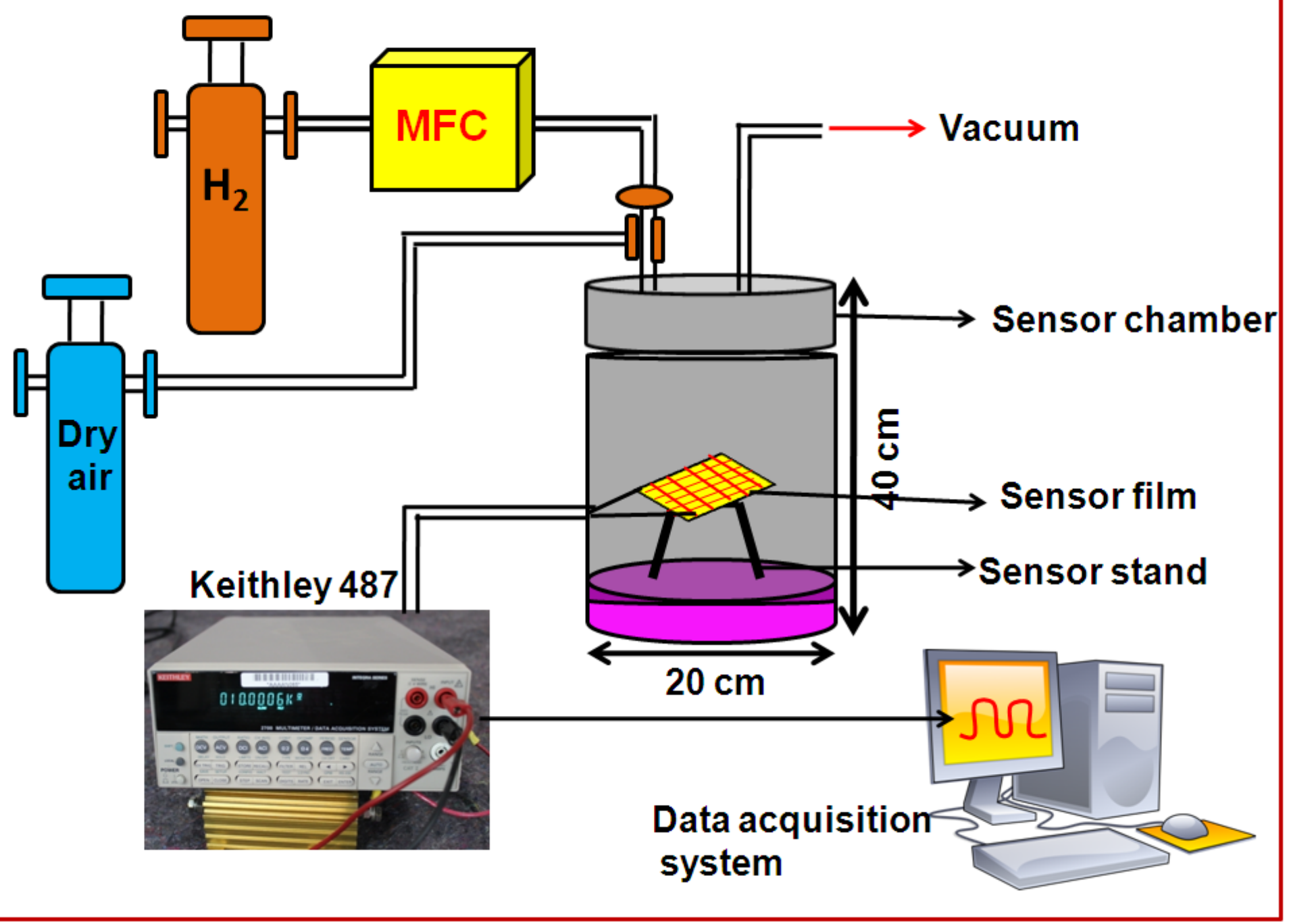

Figure 1

Schematic representation of the gas sensor setup 


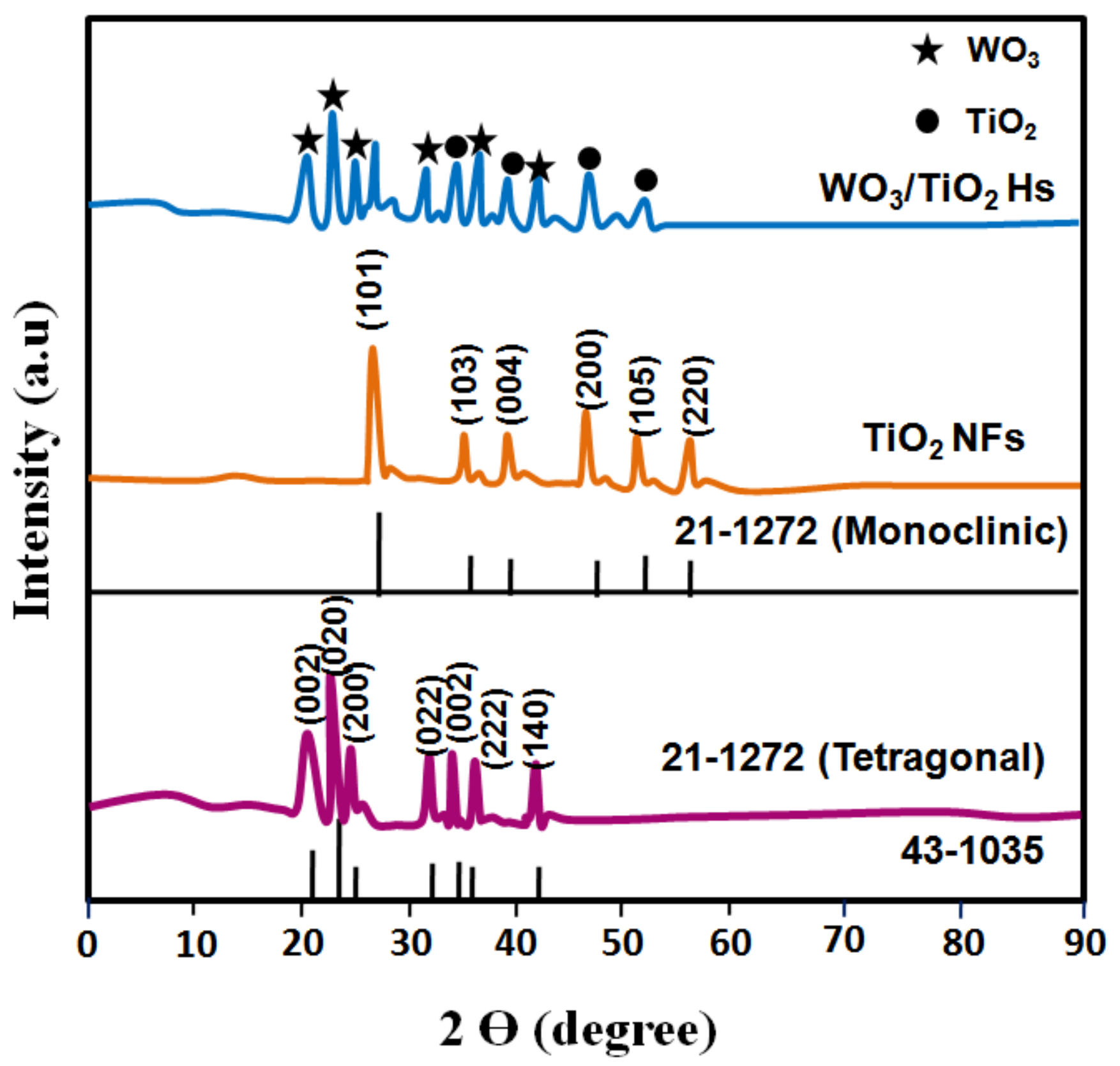

Figure 2

X-ray diffraction pattern of the sensor films 


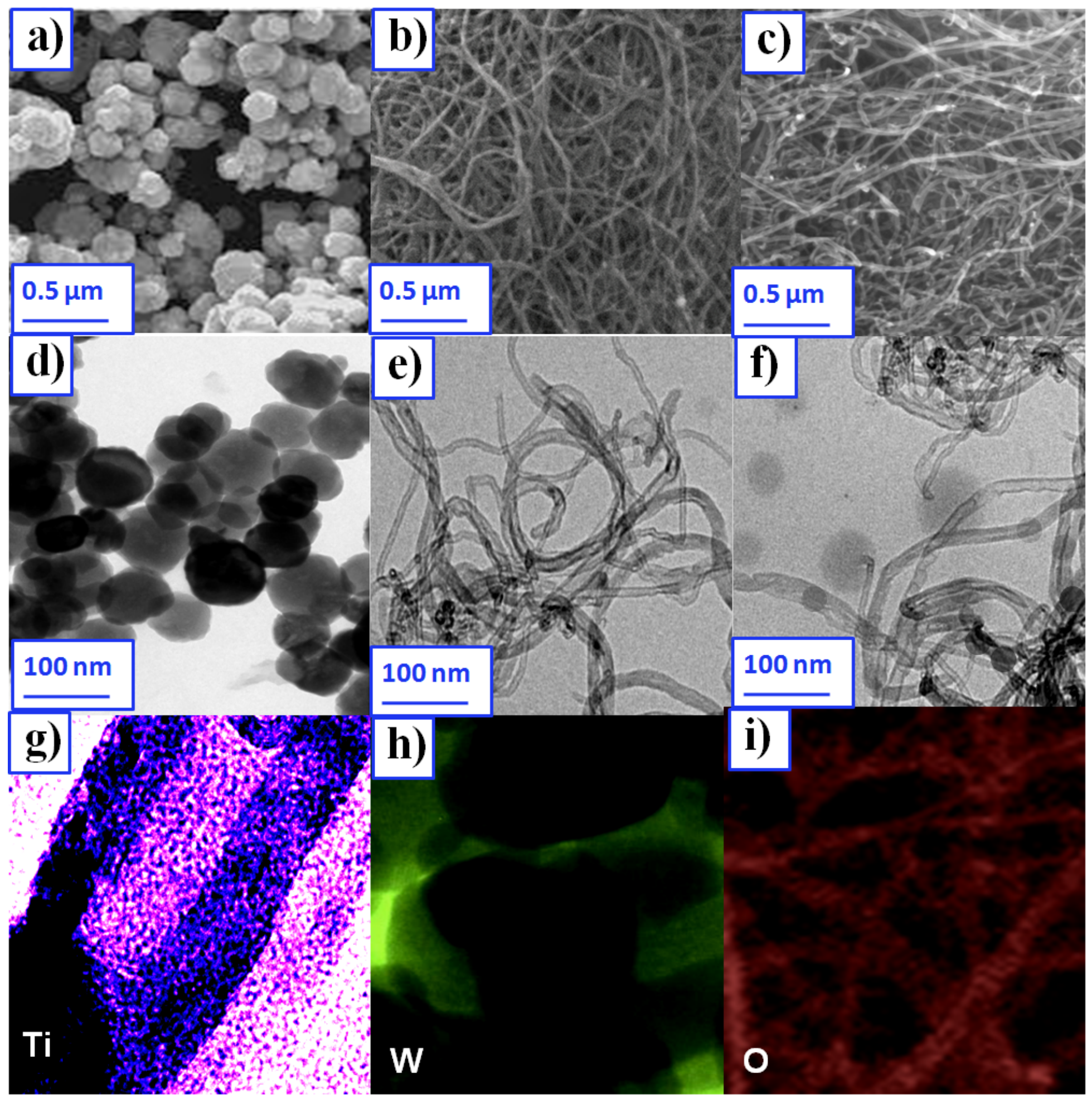

Figure 3

SEM images of (a) WO3 NPs; (b) TiO2 NFs; (c) WO3/TiO2 Hs; TEM images of (d) WO3 NPs; (e) TiO2 NFs; (f) WO3/TiO2 Hs; Elemental mapping of (g) Ti; (h) W and (i) $\mathrm{O}$ 


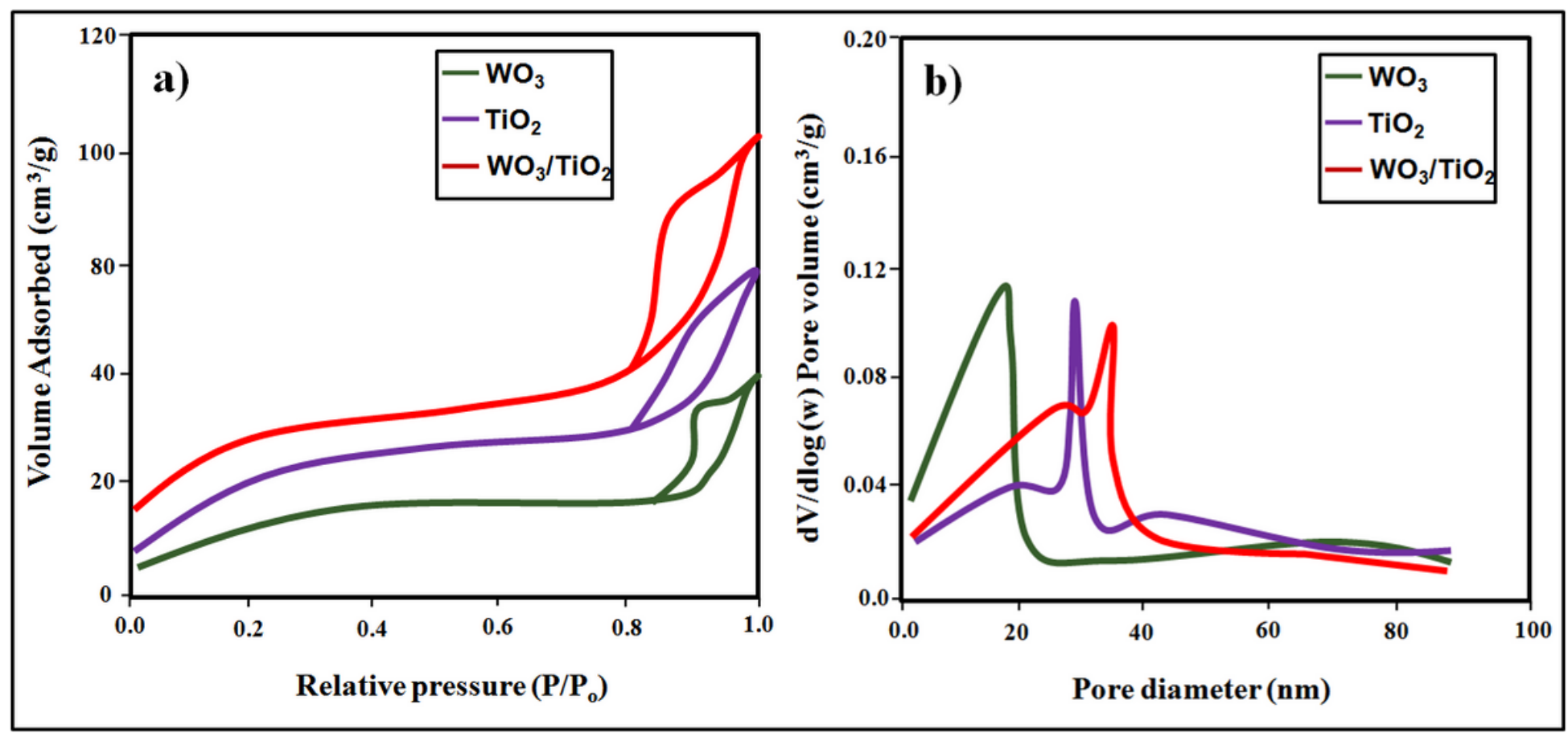

Figure 4

Raman spectra of the sensor films 


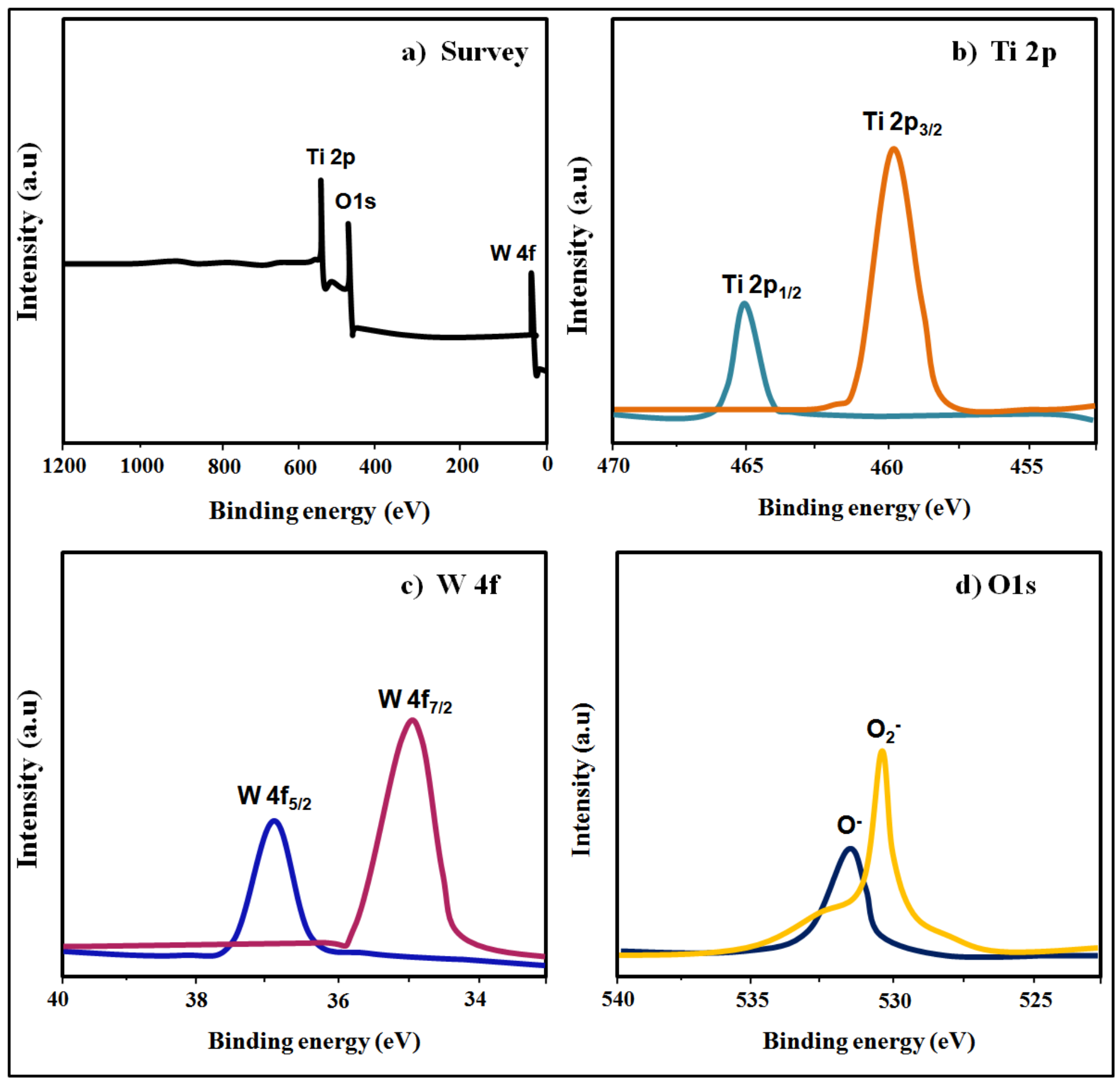

Figure 5

XPS spectra of WO3/TiO2 Hs (a) survey; (b) Ti 2p; (c) W 4 f and (d) 0 1s 


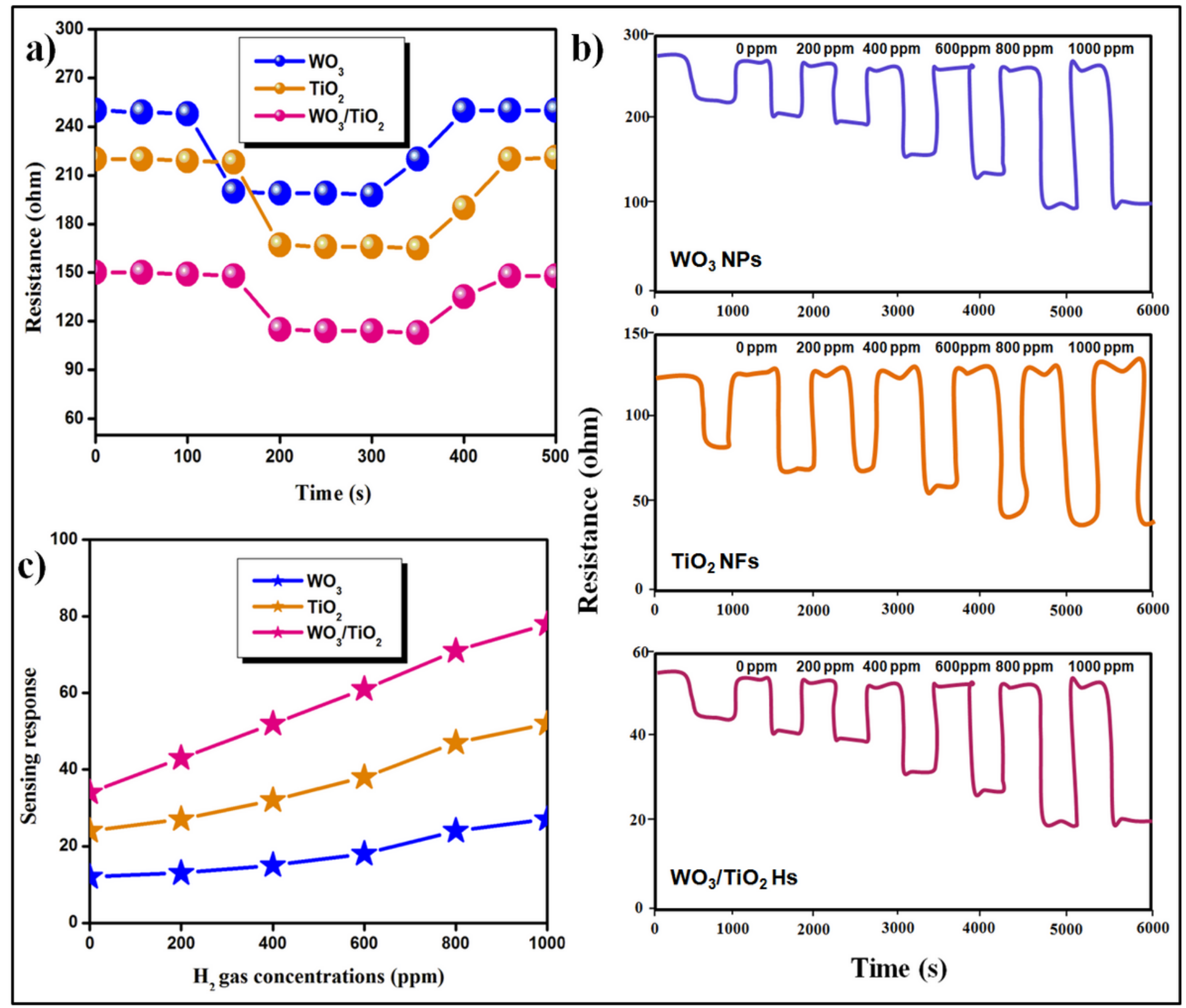

Figure 6

(a) Variation of resistance value of the sensors; Dynamic response of (b) WO3 NPs;; TiO2 NFs, W03/TiO2 $\mathrm{Hs}$; c) Sensing response of $\mathrm{H} 2$ 


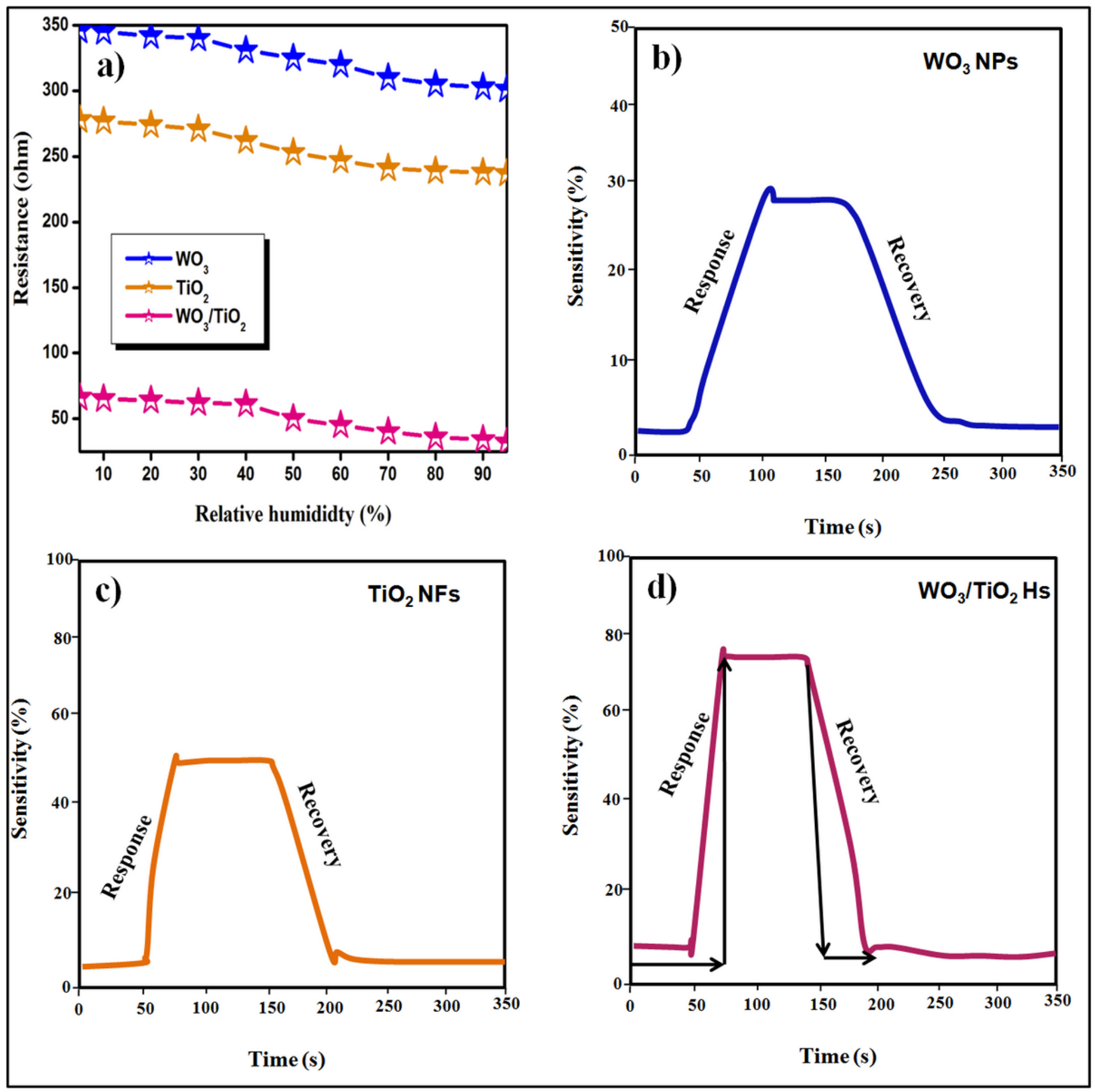

Figure 7

(a) Effect of humidity on the resistance of the sensors; Response and recovery time of the $\mathrm{H} 2 \mathrm{gas}$ (b) WO3 NPs; (c) TiO2 NFs; (d) WO3/TiO2 Hs; 


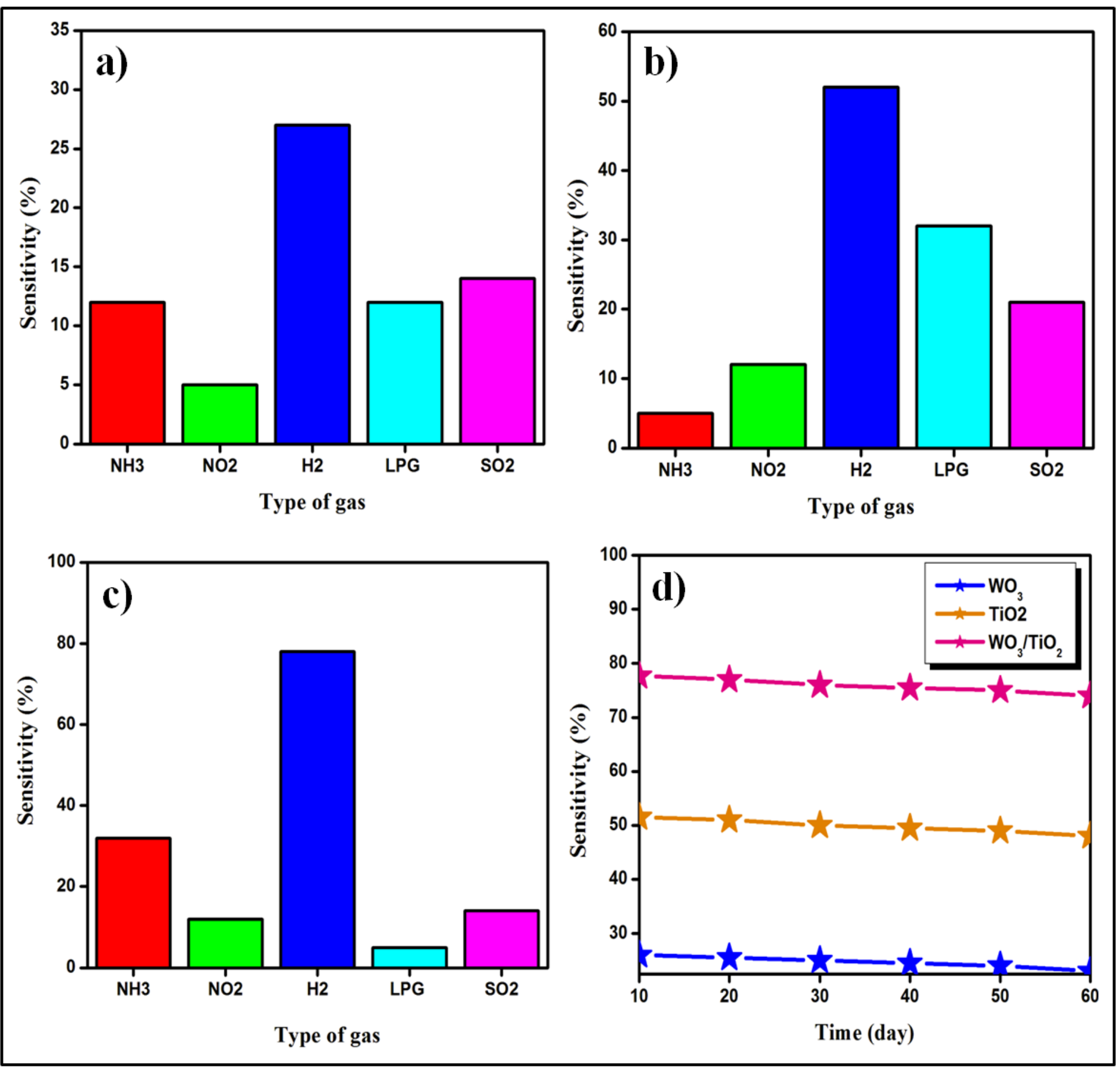

Figure 8

Selectivity gas sensing test of (a) WO3 NPs; (b) TiO2 NFs; (c) WO3/TiO2 Hs; (d) Stability test of all the sensor films 


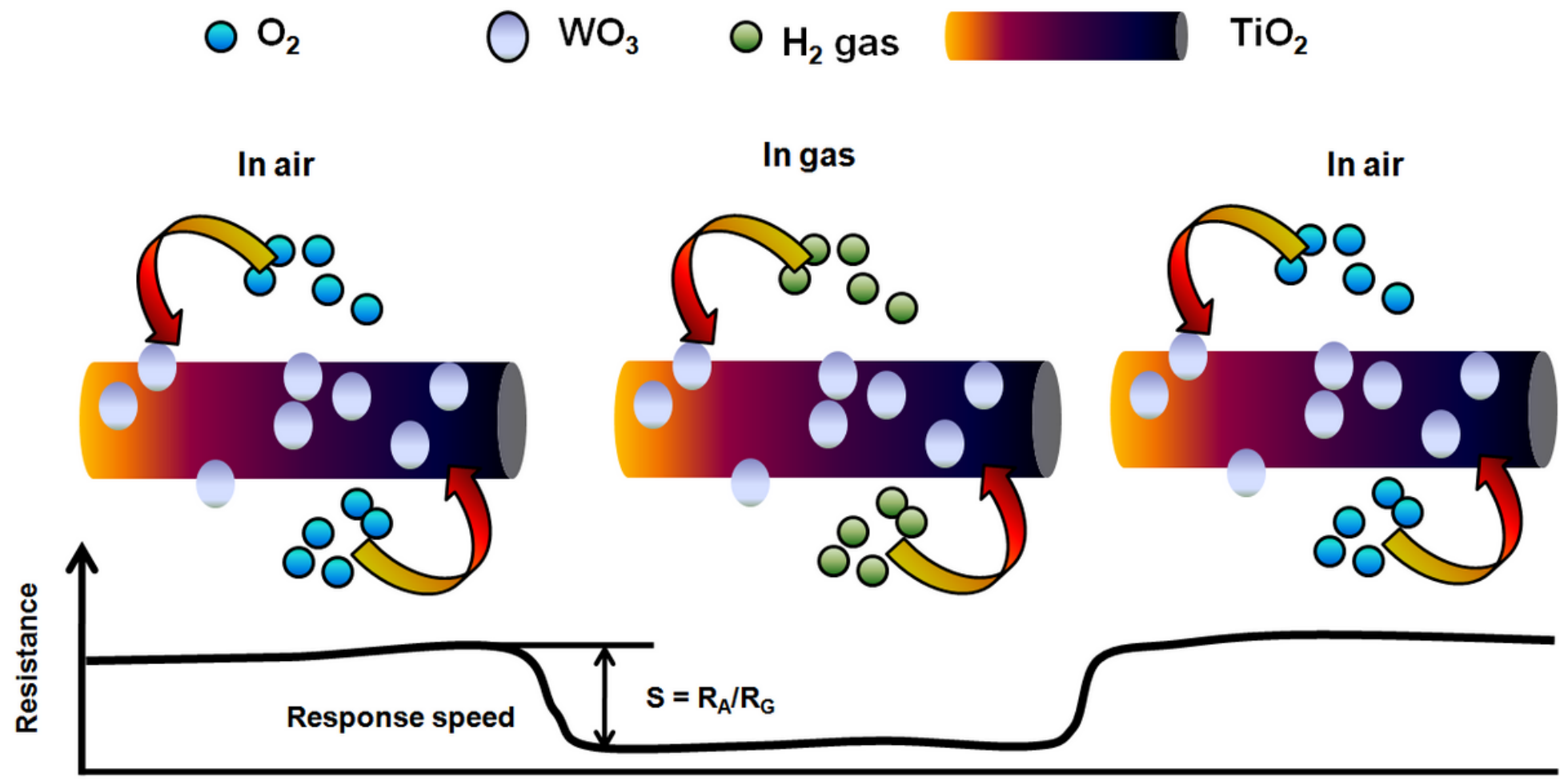

Time

Figure 9

Gas sensing mechanism

\section{Supplementary Files}

This is a list of supplementary files associated with this preprint. Click to download.

- Table1.doc 